\title{
An electret-based energy harvesting device with a wafer-level fabrication process
}

\section{Crovetto, Andrea; Wang, Fei; Hansen, Ole}

Published in:

Journal of Micromechanics and Microengineering

Link to article, DOI:

10.1088/0960-1317/23/11/114010

Publication date:

2013

Link back to DTU Orbit

Citation (APA):

Crovetto, A., Wang, F., \& Hansen, O. (2013). An electret-based energy harvesting device with a wafer-level fabrication process. Journal of Micromechanics and Microengineering, 23(11), 114010.

https://doi.org/10.1088/0960-1317/23/11/114010

\section{General rights}

Copyright and moral rights for the publications made accessible in the public portal are retained by the authors and/or other copyright owners and it is a condition of accessing publications that users recognise and abide by the legal requirements associated with these rights.

- Users may download and print one copy of any publication from the public portal for the purpose of private study or research.

- You may not further distribute the material or use it for any profit-making activity or commercial gain

- You may freely distribute the URL identifying the publication in the public portal

If you believe that this document breaches copyright please contact us providing details, and we will remove access to the work immediately and investigate your claim 


\title{
Electret Based Energy Harvesting Device with Wafer Level Fabrication Process
}

\author{
Andrea Crovetto ${ }^{1,2}$, Fei Wang ${ }^{1}$, and Ole Hansen ${ }^{1,3}$ \\ ${ }^{1}$ Department of Micro- and Nanotechnology, Technical University of Denmark, DTU \\ Nanotech, Building 345E, DK-2800 Kgs. Lyngby, Denmark \\ 2 Politecnico di Milano, Italy \\ ${ }^{3}$ CINF - Center for Individual Nanoparticle Functionality, Technical University of \\ Denmark, Building 345E, DK-2800 Kgs. Lyngby, Denmark \\ E-mail: fei.wang@nanotech.dtu.dk
}

\begin{abstract}
.
This paper presents a MEMS energy harvesting device which is able to generate power from two perpendicular ambient vibration directions. CYTOP polymer is used both as the electret material for electrostatic transduction and as a bonding interface for low-temperature wafer bonding. The device consists of a four-wafer stack, and the fabrication process for each wafer layer is described in detail. All the processes are performed at wafer scale so that overall 44 devices can be fabricated simultaneously on one 4-inch wafer. The effect of fabrication issues on the resonant frequency of the device is also discussed. With a final chip size of about $1 \mathrm{~cm}^{2}$, a power output of $32.5 \mathrm{nW}$ is successfully harvested with an external load of $17 \mathrm{M} \Omega$, when a harmonic vibration source with RMS acceleration amplitude of $0.03 \mathrm{~g}\left(\sim 0.3 \mathrm{~m} \cdot \mathrm{s}^{-2}\right)$ and resonant frequency of $179 \mathrm{~Hz}$ is applied. These results can be improved in an optimized design.
\end{abstract}




\section{Introduction}

Recently, energy harvesting devices have been developed based on electromagnetic $[1,2,3]$, piezoelectric $[4,5]$, and electrostatic $[6,7,8,9,10,11,12,13,14]$ transduction methods due to their potential to replace batteries used in wireless sensor network (WSN) technology $[15,16]$. Electromagnetic energy harvesting devices are built on Faraday's law of induction, where electric power generates when a number turns of coil cut across a magnetic field. Piezoelectric harvesters utilize the piezoelectric effect of certain materials, such as PZT and PVDF, which are electrically polarized when subjected to mechanical strain. Electrostatic energy harvesters use variable capacitors which either have been pre-charged using electret materials, or biased by external voltage sources. When driven by a vibration source, the change of capacitance forces charge movement between the electrodes and therefore generates electric current through an external load resistor.

The capacitance of an ideal parallel-plate capacitor is $C=\epsilon_{r} \epsilon_{0} A / g$, where $\epsilon_{r}$ is the relative permittivity of the dielectric (e.g. air), $\epsilon_{0}$ the permittivity of vacuum, $A$ the electrode overlap area, and $g$ the air gap between the two electrodes. According to this, there are two main schemes to change the capacitances by changing either the overlap area or the gap distance between the two electrodes of the capacitor. The former scheme can be achieved by in-plane vibration of the proof mass where the overlapping area changes; while the latter scheme can be achieve by out-of-plane vibration of the proof mass to change the air gap. Since the squeeze-film air damping effect is relatively more profound than the slide-film damping under the same conditions, energy harvesting devices with in-plane vibration scheme have higher Q-factor and less energy loss by viscous dissipation, compared to devices with an out-of-plane vibration scheme.

In our previous work [13], we have developed a prototype device where an output power of $1.2 \mu \mathrm{W}$ was successfully harvested from an external vibrations with acceleration as low as $0.014 \mathrm{~g}\left(\sim 0.14 \mathrm{~m} \cdot \mathrm{s}^{-2}\right)$. However, the two parts (a silicon chip and a glass chip) of the prototype device were bonded by double-sided adhesive tape. It is neither practical for mass production nor compatible to the fabrication of sensors. In this paper, we will therefore focus on a MEMS fabrication process at wafer-level for the electretbased energy harvesting device. Thanks to the compatible processes, it is promising for the devices to be fabricated and packaged together with the wireless sensors in the future. The device described here can be further optimized for higher output power and voltage.

\section{Design and Modeling}

As shown in Fig. 1, we have developed an electrostatic energy harvesting device with a 4-wafer stack structure. This device includes a suspended proof mass that is confined within a fixed frame through spring structures. The springs are designed to provide a sharp resonance peak in the ambient vibration frequency range (less than $200 \mathrm{~Hz}$ ). 


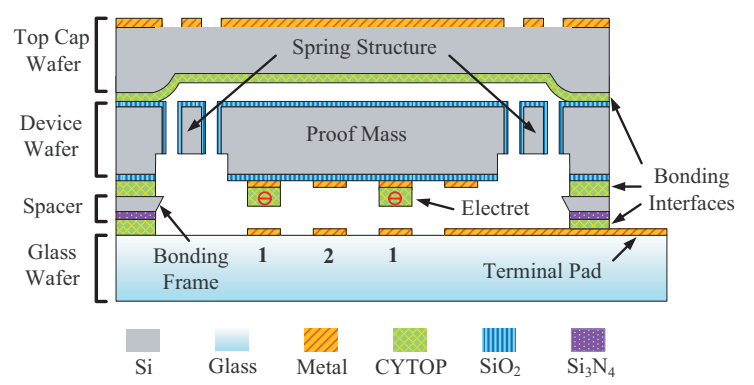

Figure 1. Schematic view of the 4-wafer stack structure for the energy harvesting device. The device is composed of four wafers, namely, Top Cap, Device, Spacer and Glass. The four wafers are bonded together with adhesive polymer in a thermocompression bonding technique.

Two perpendicular in-plane vibration directions can drive the proof mass with this method. CYTOP polymer is used both as an electret material and adhesive layers for low-temperature wafer bonding. As the pre-charged electrets oscillate according to the vibration source, induced charges will move between the two electrodes on the counter part causing a current through the external load.

Similar to our previous work [13], we use the electrodes on single side (ESS) design in which output electrodes are located on the same side of the device. This ESS design releases the package challenge of the electrodes on both sides (EBS) design, where additional wiring or 3D structures such as metal stud bumps are demanded to lead out the signal lines from both sides of the device. Furthermore, moving parts and electrets are completely encapsulated to keep them dust- and moisture-free for better charge stability and overall performance. Unlike the previously reported prototype harvesters $[9,11,12,13]$, the device presented here is a fully packaged device entirely built at a wafer level. Besides, the gap between electrets and counter electrodes is tunable and well controlled in the fabrication phase. The small device size $(1 \mathrm{~cm} \times 1 \mathrm{~cm} \times 0.15 \mathrm{~cm})$ makes it compatible with the state-of-the-art WSN technology.

Figure 2 shows the layout of the proof mass and the beam structures. With two beams on each side, the proof mass is suspended from the frame, which allows two directional movement driven by the external vibration source. With the inclusion of stopper structures, the maximum vibration amplitude of the proof mass can be limited, to prevent fracture of the silicon beam material at high accelerations. Figure 3 shows 3-D simulations by COMSOL finite element modeling to obtain the resonant frequency (Fig. 3 a) and the stress distribution in the beams (Fig. 3 b). When a displacement of $500 \mu \mathrm{m}$ is defined for the proof mass, the maximum stress across the beam is simulated to be $800 \mathrm{MPa}$, which is far smaller than the fracture limit of single crystal silicon (up to $\sim 7 \mathrm{GPa}[17]$ ), leaving a large safety margin for overload of the structure without risk of fracture. The resonant frequencies in $x$ and $y$ directions can be easily optimized by tuning the beam length $L$ and the beam width $w$. Detailed parameters of the device are listed in Table 1.

Figure 4 shows a model of the device which contains both the electric and the 

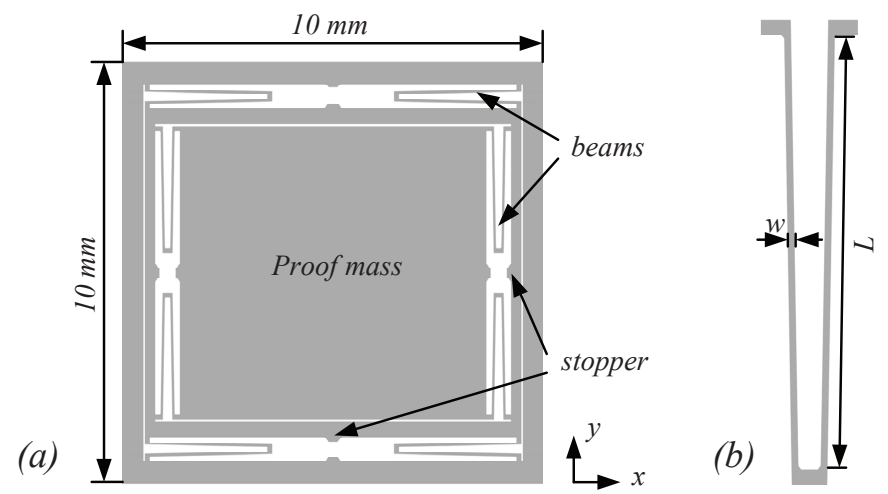

Figure 2. (a)Layout for the Device structure with proof mass suspended by beams in $x$ and $y$ directions; (b) Close-up view of the beam structure.

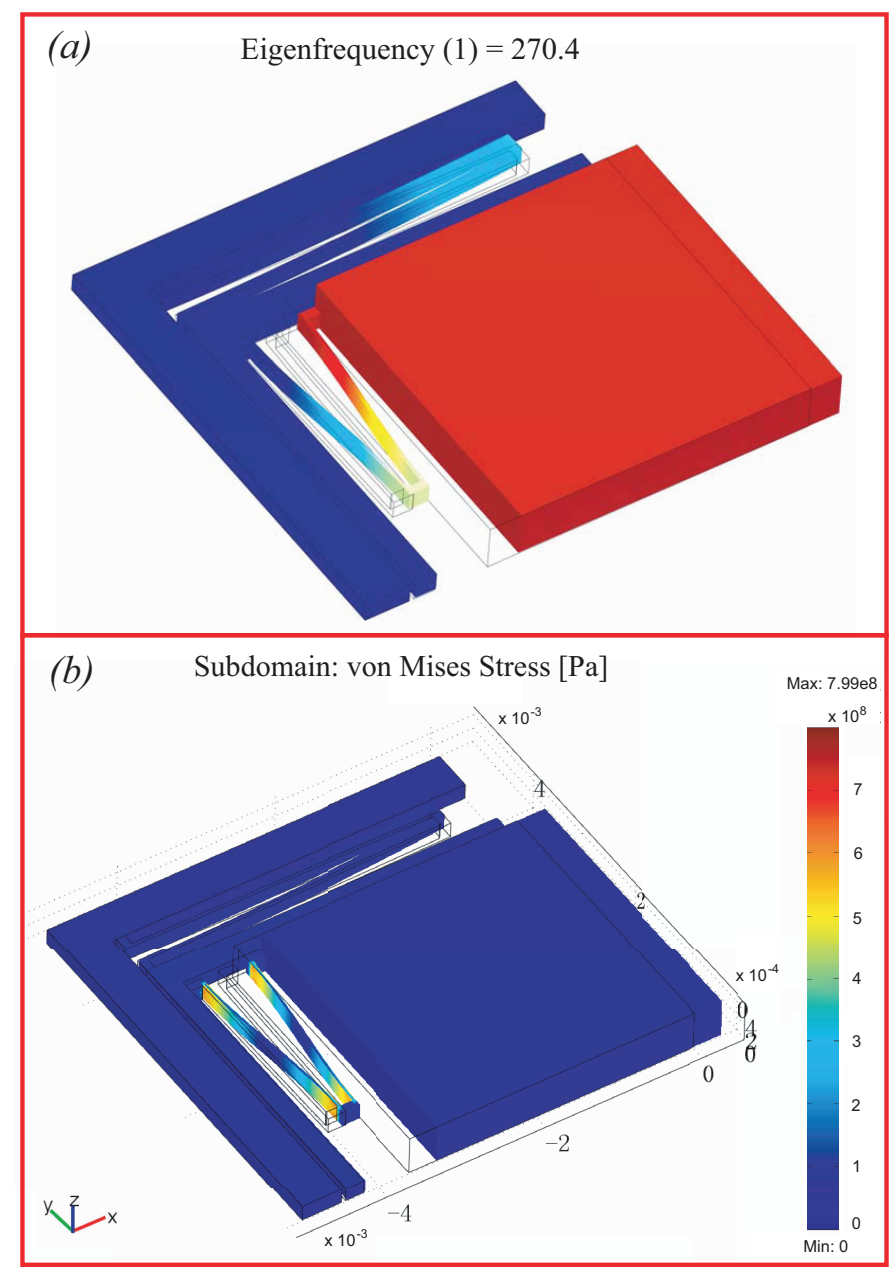

Figure 3. 3-D FEM simulations (a) Eigenfrequency study and (b) Static study. The maximum stress at the corner of the beam structure is less than $800 \mathrm{MPa}$ when the displacement of the proof mass is defined as $500 \mu \mathrm{m}$.

mechanical domains. According to the Kirchhoff's voltage law, the voltage across the 
Table 1. Parameters of the electret-based energy harvesting device.

\begin{tabular}{l|l|l}
\hline Parameters & Value & Description \\
\hline$g$ & $100 \mu \mathrm{m}$ & gap between the proof mass and the electrodes \\
$d$ & $10 \mu \mathrm{m}$ & electret thickness \\
$w$ & $40 \mu \mathrm{m}$ & beam width \\
$L$ & $2.3-2.8 \mathrm{~mm}$ & beam length \\
$t_{1}$ & $280 \mu \mathrm{m}$ & beam thickness \\
$t_{2}$ & $500 \mu \mathrm{m}$ & wafer thickness \\
$m$ & $0.06 \mathrm{~g}$ & proof mass \\
$f_{0}$ & $220-300 \mathrm{~Hz}$ & resonant frequency \\
$\epsilon_{d}$ & 2 & relative permittivity of the electret \\
$\sigma_{d}$ & $-0.24 \mathrm{mC} / \mathrm{m}^{2}$ & surface charge density \\
$C_{\min }$ & $1.64 \mathrm{pF}$ & minimum capacitance \\
$C_{\max }$ & $1.82 \mathrm{pF}$ & maximum capacitance \\
\hline
\end{tabular}

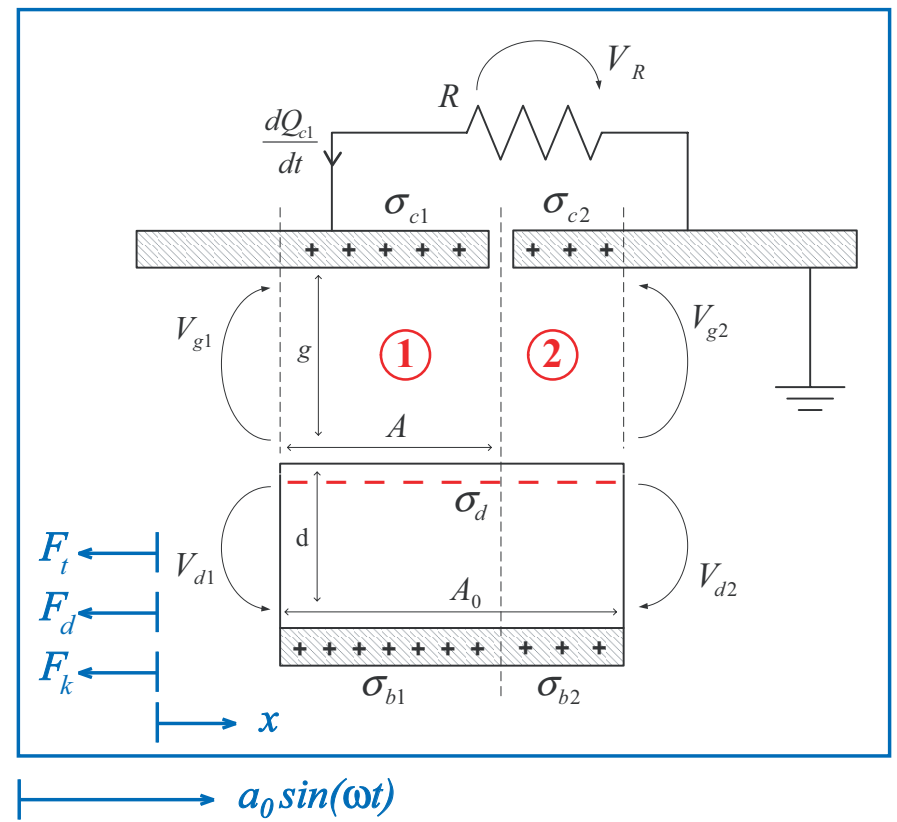

Figure 4. Model of the in-plane electret energy harvesting device.

resistor $V_{\mathrm{R}}$ fulfils

$$
\begin{aligned}
R \frac{\mathrm{d} Q(t)}{\mathrm{d} t} & =V_{\mathrm{R}}(t)=V_{\mathrm{g} 2}(t)-V_{\mathrm{d} 2}(t)+V_{\mathrm{d} 1}(t)-V_{\mathrm{g} 1}(t) \\
& =\sigma_{\mathrm{c} 2}(t) g / \epsilon_{0}-\sigma_{\mathrm{b} 2}(t) d /\left(\epsilon_{d} \epsilon_{0}\right)+\sigma_{\mathrm{b} 1}(t) d /\left(\epsilon_{d} \epsilon_{0}\right)-\sigma_{\mathrm{c} 1}(t) g / \epsilon_{0}
\end{aligned}
$$

Overall charge neutrality for the individual overlap areas requires,

$$
\sigma_{\mathrm{d}}+\sigma_{\mathrm{c} i}(t)+\sigma_{\mathrm{b} i}(t)=0,(i \in[1,2])
$$

while the constant total charge condition on the floating base electrode results in

$$
A_{0} \sigma_{\mathrm{b}}=A(t) \sigma_{\mathrm{b} 1}(t)+\left[A_{0}-A(t)\right] \sigma_{\mathrm{b} 2}(t)=\text { constant. }
$$




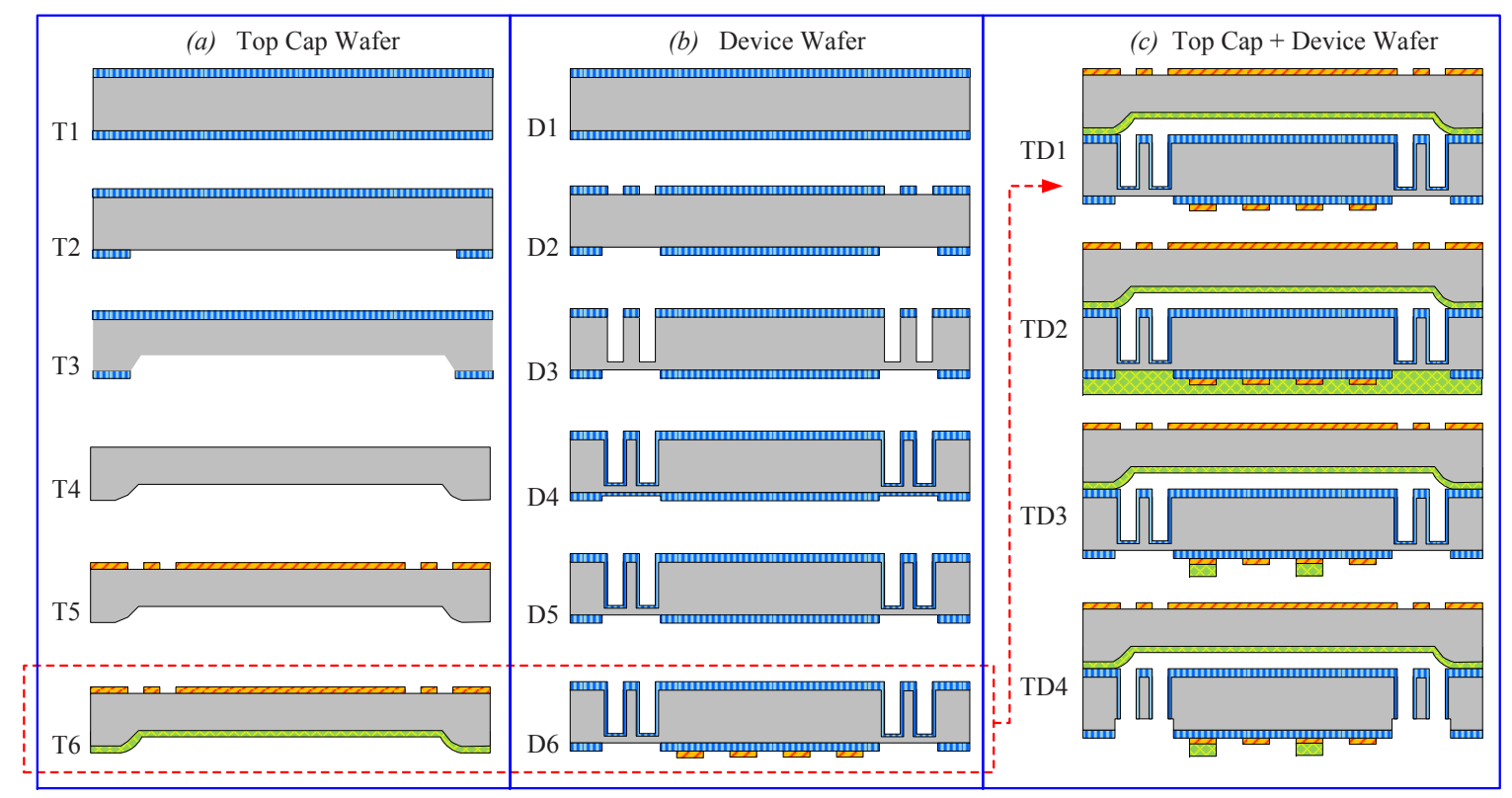

Figure 5. Process flow for the (a)Top Cap and (b)Device wafers. The two wafers are fabricated individually and then bonded together using adhesive CYTOP polymer (c).

From Eqs. 2 and 3, the governing equation for the electric behavior of the device becomes

$$
\dot{Q}=\left(-\frac{d \epsilon_{d}+g}{R \epsilon_{0} \epsilon_{d} \tilde{A}} Q-\frac{d \sigma_{d}}{R \epsilon_{0} \epsilon_{d}}\right) \cdot \frac{A_{0}}{A_{0}-\tilde{A}}
$$

where $Q=Q_{c 1}$ is the instantaneous surface charge on electrode $1, R$ the external load resistance, $\tilde{A}$ the effective overlap area, $A_{0}$ the initial overlap area. The mechanical behavior of the device can be described as

$$
\ddot{x}=a_{0} \sin (\omega t)-\omega_{0}^{2} x-2 \xi_{m} \omega_{0} \dot{x}+\frac{F_{t}}{m}
$$

where, $\omega$ and $\omega_{0}$ are the angular frequency of external acceleration and the angular resonant frequency of the spring-mass system, respectively; $\xi_{m}$ is the mechanical damping factor. The coupling between the electric and the mechanical domains is related to the transduction force $F_{t}$, which may be expressed as $F_{t}=-\partial U / \partial x$ where $U$ is the electrostatic energy stored in the device. Solving these equations with a driven acceleration of $0.03 \mathrm{~g}$, we have estimated an out power of about $30 \mathrm{nW}$ and an optimal load of $22 \mathrm{M} \Omega$ when a parasitic capacitance $(\sim 40 \mathrm{pF})$ is taken into account. More detailed discussion on design, modeling and optimization of the device will be published in the near future [18].

\section{Fabrication}

The energy harvesting device is built with 4-inch standard MEMS fabrication techniques. There are four wafers, namely, Top Cap, Device, Spacer and Glass in the structure. The material and purpose of each wafer are listed in Table 2 and the fabrication process for each wafer will be described below in detail. 
Table 2. Material and purpose of the four processed wafers in the energy harvesting device.

\begin{tabular}{|c|c|c|}
\hline Type & Material & Purpose \\
\hline Top Cap & silicon & protects critical parts (i.e. springs and electrets) from water leakage \\
\hline Device & silicon & contains proof mass, spring system, and electret pattern \\
\hline Spacing & silicon & $\begin{array}{l}\text { defines the air gap thickness between electret and counter electrode } \\
\text { patterns }\end{array}$ \\
\hline Glass & fused silica & $\begin{array}{l}\text { contains the counter electrode pattern, ending up in two conductive } \\
\text { terminals where the external load can be connected }\end{array}$ \\
\hline
\end{tabular}

\subsection{Top Cap wafer}

The Top Cap wafer of the energy harvesting device is used to protect electrets and fragile spring structures from external agents. Fabrication of the Top Cap starts with a $350 \mu$ m-thick (100) silicon wafer, as shown in Fig. 5(a).

T1: The wafer is thermally oxidized to grow $0.5 \mu$ m-thick $\mathrm{SiO}_{2}$ layers on both sides of the wafer;

T2: Then, the $\mathrm{SiO}_{2}$ layer is patterned from the bottom side by lithography and buffered hydrofluoric acid (bHF) etching. The $\mathrm{SiO}_{2}$ layer pattern will serve as the mask for following silicon etching;

T3: The silicon wafer is etched using a $25 \% \mathrm{KOH}$ solution at $85^{\circ} \mathrm{C}$ to an etch depth of $20 \mu \mathrm{m}$. The cavity depth should be controlled in a reasonable range. It should be deep enough that all the moving parts of the device are free of stiction to or collision with the cap, while it should not be too deep to spin coat a uniform CYTOP layer afterwards.

T4: All of the $\mathrm{SiO}_{2}$ layer is stripped away using bHF etching. Afterwards, a maskless etch in $\mathrm{KOH}$ for 30 seconds is performed to round the edge of the cavity, which will facilitate the polymer coating to follow;

T5: Using a lift-off technique, $50 \mathrm{~nm}$ Aluminum is evaporated and patterned on the top side of the wafer which will serve as the fiducial marks for the later bonding process;

T6: CYTOP is spin-coated twice onto the wafer at $800 \mathrm{rpm}$ for 30 seconds, which results in a thickness of about $4 \mu \mathrm{m}$ for the adhesive polymer. The Top Cap wafer is now ready for the further processing.

\subsection{Device wafer}

The Device wafer is the main component in the whole device. It contains the springmass structure and carries the polymer electret. We start fabrication of the Device wafer with a $500 \mu \mathrm{m}$-thick (100) silicon wafer with a resistivity of about $10^{-1} \Omega \cdot \mathrm{m}$.

D1: As shown in Fig. 5(b), the wafer is thermally oxidized and $2 \mu \mathrm{m}$-thick $\mathrm{SiO}_{2}$ layers are grown on both sides of the wafer; 
D2: Lithography is applied to the two sides of the wafer successively. Then, the $\mathrm{SiO}_{2}$ layers are etched by bHF;

D3: With the $\mathrm{SiO}_{2}$ as masking layer, the silicon wafer is dry etched in a deep-RIE process shaping the beam structures. A Bosch process [19] is employed with an etch depth of about $280 \mu \mathrm{m}$, which will be the final beam thickness.

D4: The wafer is then re-oxidized thermally to protect the sidewalls of the beam structures during the later final release etch;

D5: RIE etching of $\mathrm{SiO}_{2}$ is performed from the bottom side to expose the area to be released later;

D6: A metal multilayer of $\mathrm{Cr} / \mathrm{Au} / \mathrm{Cr}(10 / 300 / 40 \mathrm{~nm})$ for guard electrodes is deposited and patterned by lift-off technique.

Afterwards, the Top Cap wafer and the Device wafer are bonded together, as shown in Fig. 5(c).

TD1: The Top Cap wafer and the Device wafer are aligned and thermally bonded in an EVG-NIL system. The bonding is done at $160^{\circ} \mathrm{C}$ for 1 hour to achieve a high bonding strength;

TD2: CYTOP is spin-coated for 6 times to reach a final thickness of $10 \mu \mathrm{m}$;

TD3: Then, the CYTOP layer is patterned by photoresist lithography and etched in a RIE process optimized for high selectivity to the photoresist mask [20];

TD4: With another thick photoresist mask, the beam structure is released by a deepRIE etching from the bottom side. A standard recipe for deep-RIE burns the photoresist during the etching, as shown in Fig. 6(a). This is because the heat transfer is not efficient when the spring structures are fully released. To overcome this process challenge, we use the standard recipe at the beginning and switch to a revised recipe when less than $10 \mu \mathrm{m}$ silicon is left before the full release. As shown in Table 3, the revised recipe employs lower power with shorter etch time, and a standby step every 10 cycles during which plasma is switched off and wafer cooling is allowed. Figure 6(b) shows a microscopic view of the structure etched using the revised recipe. The photoresist is successfully stripped away and no burned resist residues can be seen on the proof mass and electret pattern.

Figure 7(a) shows an image of the wafer after bonding. Overall 44 devices have been fabricated simultaneously on the wafer and a close-up view can be seen in Fig. 7(b). The SEM images in Fig. 8 show more fabrication details about the electrets and the springs in $x$ and $y$ directions.

\subsection{Spacer wafer}

It is crucial to control the air gap between the electret and the counter electrodes to achieve a high power output without electrostatic collapse. Micro balls [12] or doublesided tape [13] were used for prototype devices but they are not applicable for wafer 


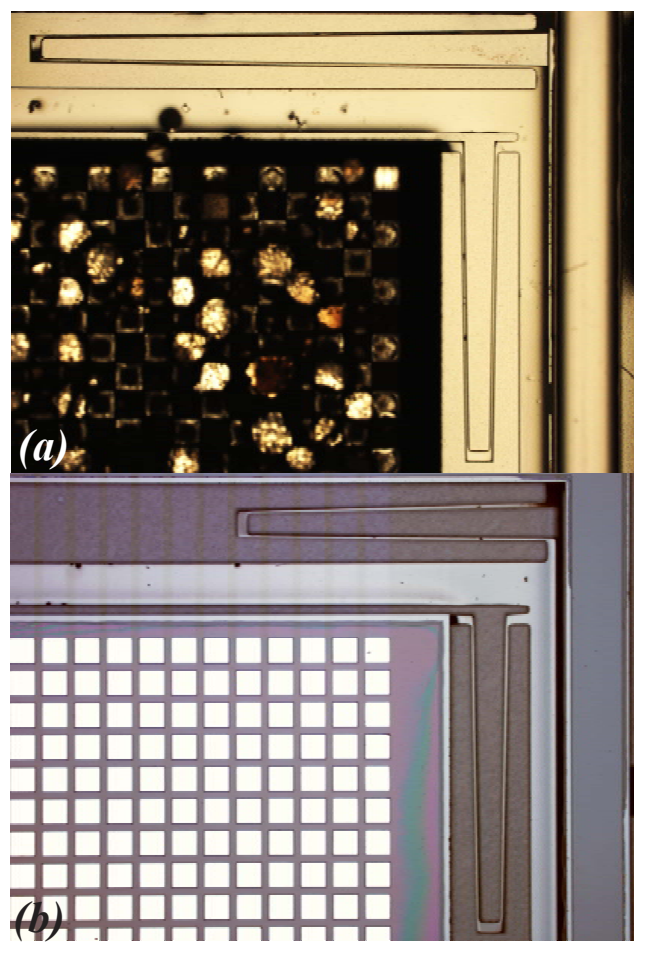

Figure 6. Microscope pictures showing release etch results with different DRIE recipes. (a): Only standard recipe: resist is burned on the whole proof mass and the electret pattern is degraded. Subsequent resist strip-off will leave resist residues on the substrate. (b): Standard recipe + revised recipe: resist is kept under a critical temperature to effectively mask the release etching process. Subsequent resist strip-off is successful and no resist residue is left on the surface.

Table 3. DRIE parameters and performance of recipes used in step TD4. A standard recipe for deep etching and a revised recipe for better cooling during the last a few $\mu \mathrm{m}$ of silicon are compared.

\begin{tabular}{l|c|c}
\hline & $\begin{array}{c}\text { Standard recipe } \\
\text { (etch/passivation) }\end{array}$ & $\begin{array}{c}\text { Revised recipe } \\
(\text { etch/passivation })\end{array}$ \\
\hline Step time (second) & $7.8 / 5.0$ & $6.0 / 5.0$ \\
$\mathrm{SF}_{6}, \mathrm{O}_{2} / \mathrm{C}_{4} \mathrm{~F}_{8}(\mathrm{sccm})$ & $230,23 / 120$ & $200,20 / 120$ \\
Coil power $($ Watt) & $2800 / 1000$ & $600 / 600$ \\
Platen power (Watt) & $19 / 0$ & $10 / 0$ \\
Platen temperature $\left({ }^{\circ} \mathrm{C}\right)$ & 0 & 20 \\
Standby step time & N.A. & 2 minutes / 10 cycles \\
Silicon/resist selectivity & $40: 1$ & $80: 1$ \\
Etch rate $(\mu \mathrm{m} /$ cycle) & 1.2 & 0.28 \\
\hline
\end{tabular}

level fabrication. Therefore, a Spacer wafer is introduced in between the Device wafer and the Glass wafer to accurately control the gap as shown in Fig. 9(a).

S1: A silicon wafer with thickness of $350 \mu \mathrm{m}$ is first oxidized in a furnace using the same recipe as step D1. The $2 \mu \mathrm{m}$-thick $\mathrm{SiO}_{2}$ will serve as the mask layer in a later $\mathrm{KOH}$ etching;

S2: The $\mathrm{SiO}_{2}$ layer is patterned by photolithography and bHF etching; 


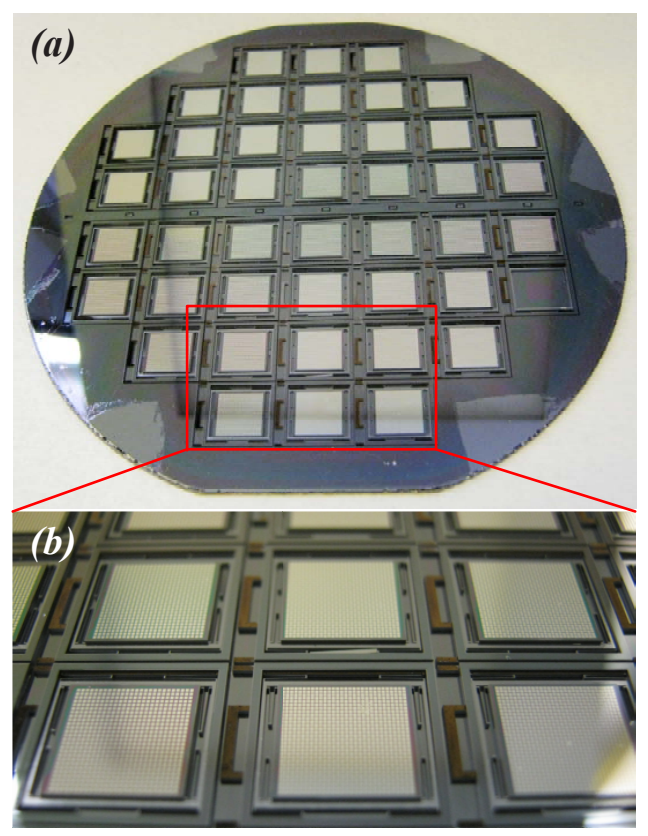

Figure 7. The Top Cap + Device wafer after step TD4. Overall 44 devices are fabricated on a single wafer. Full wafer view shown in (a) and a close up view in (b).

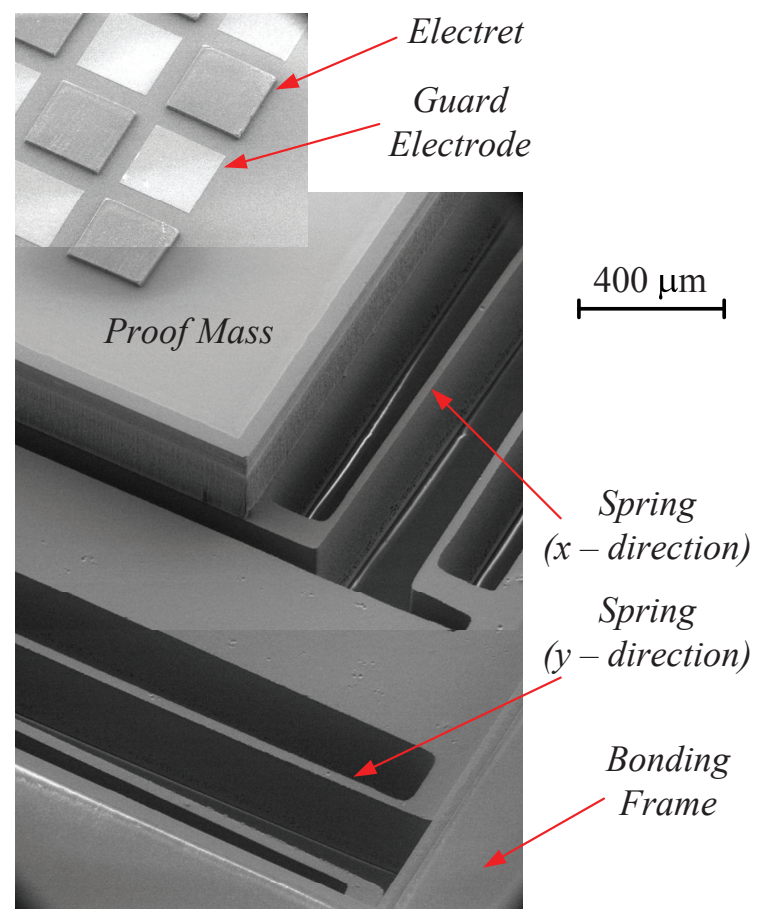

Figure 8. Multiple SEM images of device wafer's bottom side after final release of spring structure. (re-edited for better illustration.)

S3: The silicon wafer is etched in a $25 \% \mathrm{KOH}$ solution at $85^{\circ} \mathrm{C}$ to an etch depth of $100 \mu \mathrm{m}$. This will approximately be the gap distance between the electrets and the counter electrodes;

S4: After stripping all of the $\mathrm{SiO}_{2}$ layer, a $200 \mathrm{~nm}$ layer of $\mathrm{SiN}_{x}$ is deposited on the 


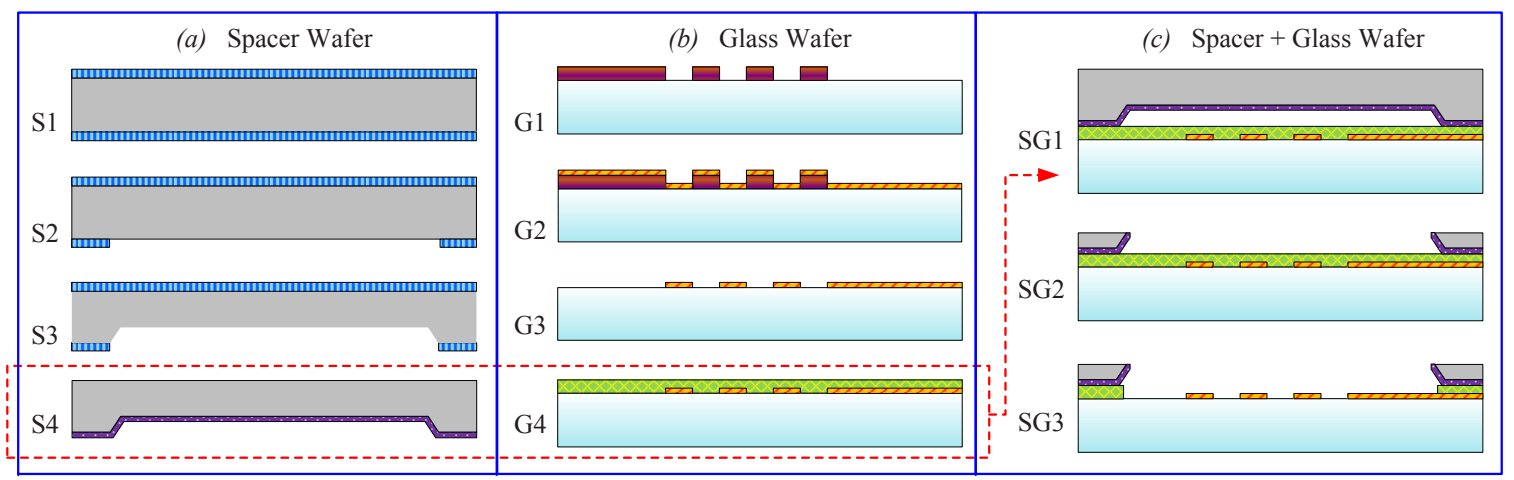

Figure 9. Process flow for the (a) Spacer and (b) Glass wafers; (c)Then, the two wafers are bonded using CYTOP.

etched cavity using a low-stress PECVD process.

\subsection{Glass wafer}

The Glass wafer contains the counter electrodes pattern, leading the current signal out to two terminals where the external load can be connected. Fused silica wafers with thicknesses of $500 \mu \mathrm{m}$ are used and the fabrication is shown in Fig. 9(b).

G1: A negative lithography is performed with a $4.2 \mu$ m-thick photoresist layer;

G2: A metal multilayer stack of $\mathrm{Cr} / \mathrm{Au} / \mathrm{Cr}(10 / 300 / 40 \mathrm{~nm})$ is deposited on the photoresist pattern;

G3: A lift-off process is performed in acetone and the electrodes pattern is left when all the photoresist is stripped;

G4: Then, CYTOP is spin-coated twice onto the wafer at $800 \mathrm{rpm}$ for 30 seconds. As in step T6, the adhesive CYTOP layer will serve as the bonding interface in the following process.

Afterwards, the Spacer and the Glass wafers are aligned and thermally bonded (Fig. 9c, SG1).

SG2: The bonded wafer is further thinned in $\mathrm{KOH}$ etching until the pre-etched cavity is exposed. Figure 10 shows a microscopic view of the wafer after etching. Part of the $\mathrm{SiN}_{x}$ membrane still remains on the wafer and will be removed in the next step;

SG3: After removal of the residual $\mathrm{SiN}_{x}$, RIE is used to etch out the CYTOP and expose the electrodes.

\subsection{Corona charging and Final bonding}

The Top Cap + Device wafer is charged in a custom-built corona charging setup as discussed in [21]. The setup consists of a high-voltage probe tip $\left(V_{H}=-10 \mathrm{kV}\right)$, a mesh grid $\left(V_{g}=-500 \mathrm{~V}\right)$ and a grounded wafer stage. The surface potential of the electret 


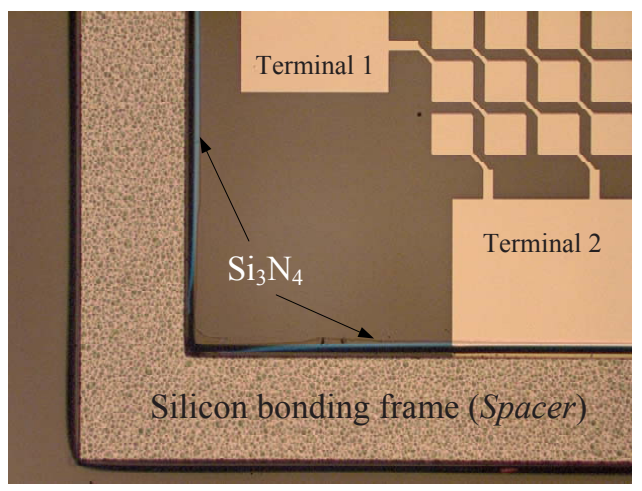

Figure 10. Microscope view of successful KOH etching (SG2). Some $\mathrm{Si}_{3} \mathrm{~N}_{4}$ (blue) is still attached to the bonding frame edges and will be removed later.

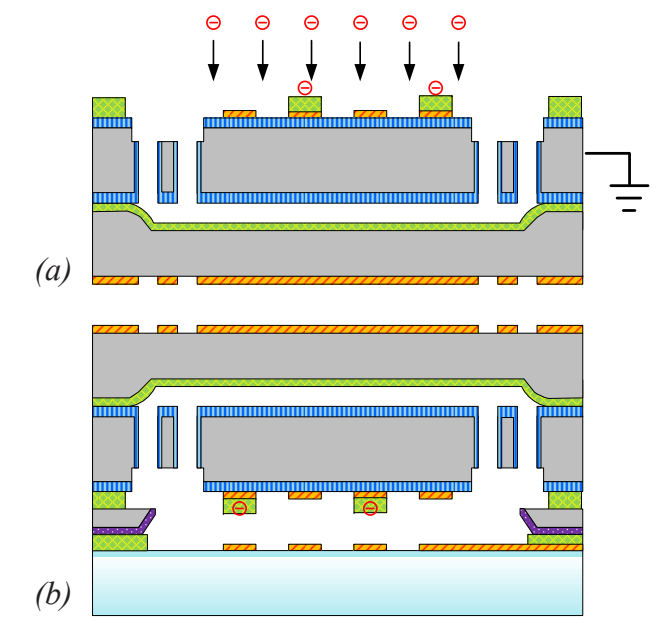

Figure 11. (a)The Top Cap + Device wafer is charged in a corona charging setup; afterwards, (b) the four wafers are finally bonded together at a low temperature of $120^{\circ} \mathrm{C}$ for 1 hour.

(array with $200 \mu \mathrm{m} \times 200 \mu \mathrm{m}$ square patterns) was measured to about $-140 \mathrm{~V}$ after charge stabilization for a few minutes. The measured surface potential is lower than the mesh grid bias voltage. This is mainly due to the fact that the charging efficiency is lower for smaller electret patterns [14, 22].

As shown in Fig. 11(b), the Top Cap + Device wafer is finally bonded to the Spacer + Glass wafer. The bonding is processed at a low temperature of $120^{\circ} \mathrm{C}$ for 1 hour to avoid any loss of the surface charge. The fabricated wafer is then diced and the final device is shown in Fig. 12. The chip size is as small as $1 \mathrm{~cm}^{2}$. Figure 13 shows a cross-sectional view of the 4 -wafer stack obtained by dicing through the middle of a device.

\section{Characterization and Discussion}

The performance of the energy harvester is characterized using a shaker setup to mimic the external vibration source. Figure 14(a) shows the shaker (B\&K Mini Shaker 4810) 


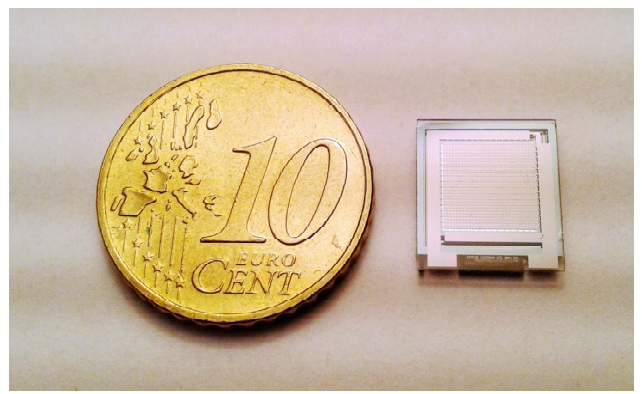

Figure 12. The final device after wafer dicing. The chip size is $1 \mathrm{~cm} \times 1 \mathrm{~cm} \times$ $0.15 \mathrm{~cm}$. The photo is taken from the glass side of the device.

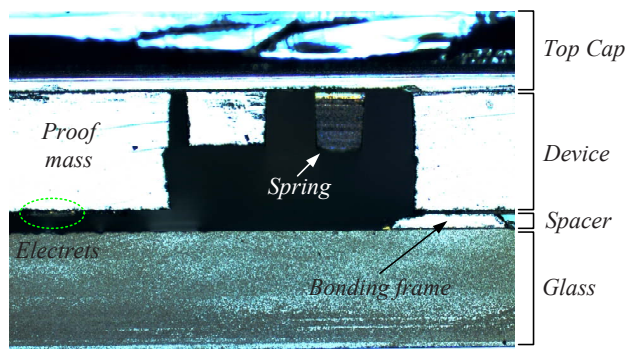

Figure 13. Cross-sectional device view from an optical microscope where a dummy device is diced in the middle of the proof mass. Proof mass, electret pattern, and a bonding frame column are seen clearly in the image. A spring connects the proof mass to the bonding frame.

with a reference accelerometer driven by an amplified sinusoidal signal from a function generator (Agilent 33220A). The two terminal electrodes are connected to an external resistor and an oscilloscope, as shown in Fig. 14(b). The root mean square (RMS) acceleration from the shaker is kept constant at $0.03 \mathrm{~g}\left(\sim 0.3 \mathrm{~m} \cdot \mathrm{s}^{-2}\right)$ using feed-back control while the frequency is swept from $172 \mathrm{~Hz}$ to $184 \mathrm{~Hz}$. The voltage output of energy harvester is recorded using an oscilloscope and therefore, the RMS power output can be derived. Figure 15 plots a typical waveform for the output voltage from the oscilloscope with $R_{\text {osc }}=1 \mathrm{M} \Omega$ and $R_{\text {test }}=0$. Sub-peaks are observed simply because the vibration amplitude of the proof mass is large enough to overpass more than one electrode period during a cycle. At a shaker amplitude of $0.23 \mu \mathrm{m}$, the vibration amplitude of the proof mass was larger than $250 \mu \mathrm{m}$, which indicates a mechanical quality factor of approximately 1100 .

Figure 16 shows the frequency response of the device and a resonant frequency of about $180 \mathrm{~Hz}$ is detected when the device is driven in $x$-direction. Similar measurements have also been performed in $y$-direction where a slightly lower resonant frequency of $176 \mathrm{~Hz}$ is detected. These frequencies are lower than the expected value of $280 \mathrm{~Hz}$ from calculation because a fabrication issue occurred during the deep-RIE etching of the beams (step D3 in Fig. 5). From the microscopic images in Fig. 17, we can see that the beam width decreases from $36 \mu \mathrm{m}$ at the top to about $16 \mu \mathrm{m}$ at the bottom of the beam. This means that the cross-section of the beam is tapered and the angle of etch 
(a)

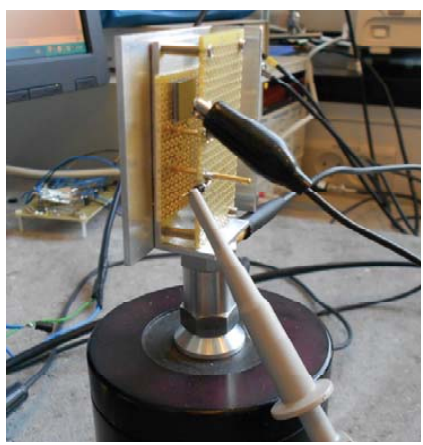

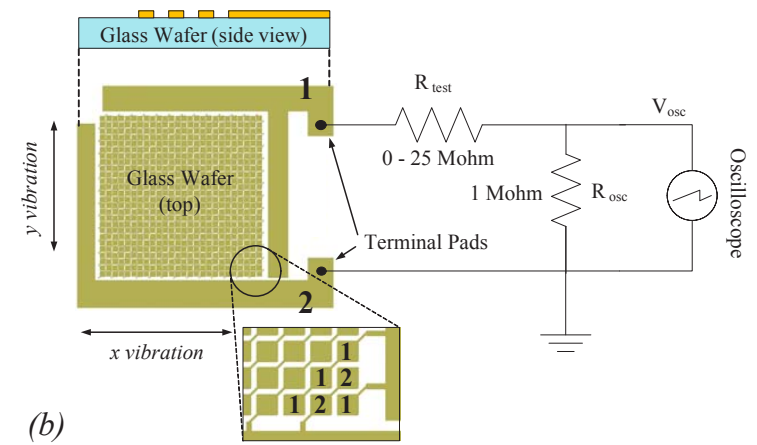

Figure 14. (a) An energy harvesting device is mounted on a shaker with a reference accelerometer and the test circuit; (b) Schematic view of the test setup. Rows of counter electrodes ' 1 ' and '2' are connected to terminal pads '1' and '2' respectively. The voltage $V_{\text {osc }}$ is measured for different values of $R_{\text {test }}$ to obtain an output power vs. load curve.

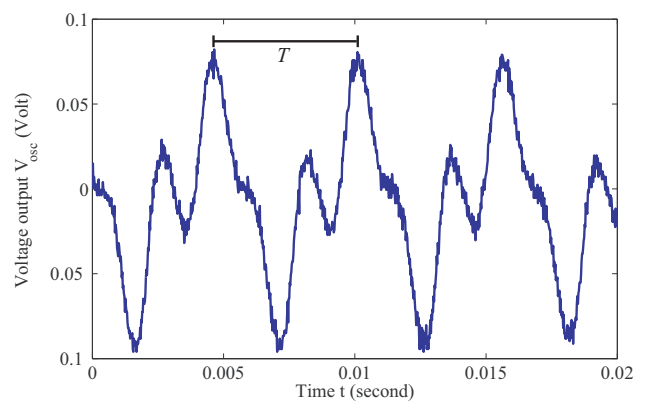

Figure 15. A typical example of the voltage output from the oscilloscope. Both a major and a minor peak is observed during a vibration cycle of the device.

profile can be calculated as:

$$
90^{\circ}+\arctan \left[\frac{\left(w_{1}-w_{2}\right) / 2}{h}\right] \simeq 92.1^{\circ}
$$

where $w_{1}$ and $w_{2}$ are the beam widths and $h$ is the etch depth. The shrinkage of beam width will dramatically reduce the area moment of inertia and therefore decrease the spring constant $k$ of the beam. From a mechanical modeling with Comsol, we have found that the spring constant of the beam decreases by about $57 \%$. According to the relation $f_{0} \propto \sqrt{k}$, we should expect a decrease of the resonant frequency by about $35 \%$, which agrees very well with our measurement.

Figure 18 shows the RMS power output as a function of the external resistance. A maximum power output of $32.5 \mathrm{nW}$ is achieved with an optimal load of $17 \mathrm{M} \Omega$. Furthermore, it was observed that comparable output powers were extracted from two perpendicular vibration directions. Due to the effect of parasitic capacitance, both the power output and the optimal load are lower than our expectation, which will be further discussed elsewhere. Nevertheless, the normalized power density (NPD) for our device, defined as power/volume/acceleration ${ }^{2}$ in [2], is as high as $1.8 \mathrm{Kg} \cdot \mathrm{s} \cdot \mathrm{m}^{-3}$. The calculated NPD value compares favorably to $1.0 \times 10^{-6} \mathrm{Kg} \cdot \mathrm{s} \cdot \mathrm{m}^{-3}$ and $0.09 \mathrm{Kg} \cdot \mathrm{s} \cdot \mathrm{m}^{-3}$ of the macro 


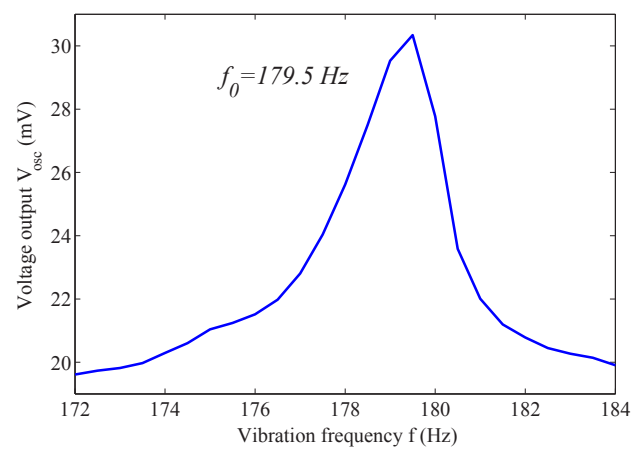

Figure 16. Voltage output from oscilloscope as a function of the driven frequency. The energy harvesting device provides a maximum voltage output when driven at the resonant frequency of $179.5 \mathrm{~Hz}$.
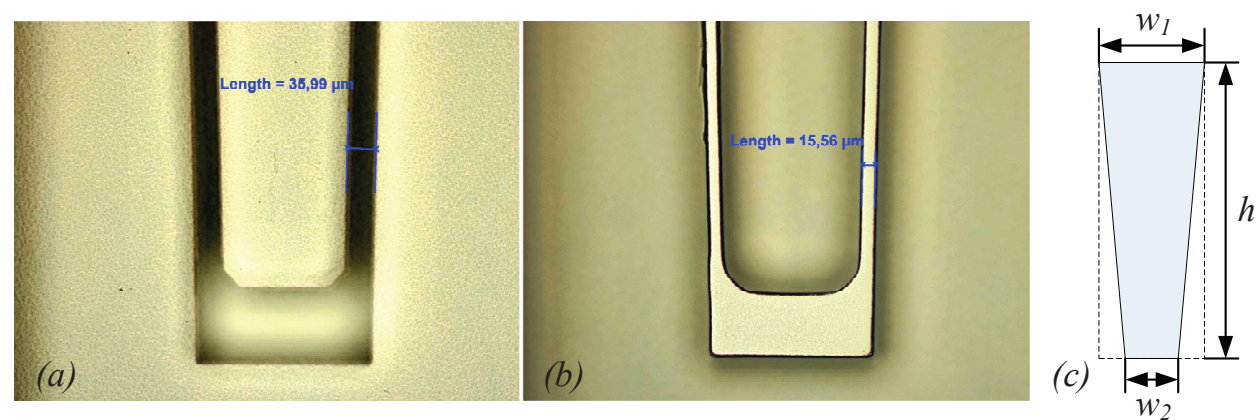

Figure 17. Beam width is measured from (a) the top side after step D3 and (b) the bottom side after step TD4. A severe shrinkage of the beam width is noticed which gives a tapered cross section of the beam, as shown in (c).

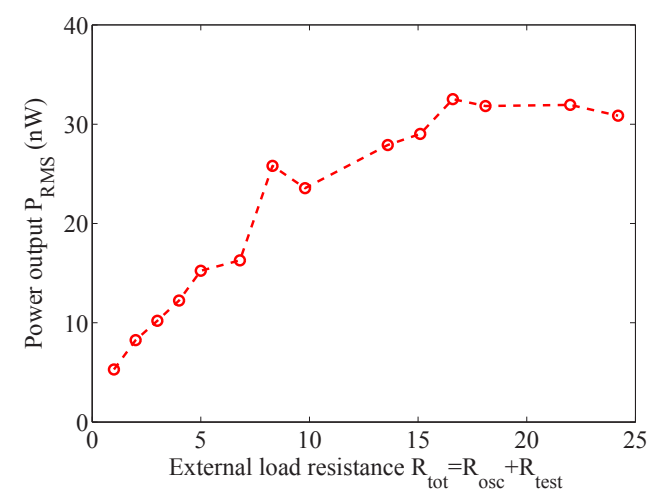

Figure 18. Harvested RMS power at $0.03 \mathrm{~g}$ as a function of the total external load $R_{\mathrm{tot}}=R_{\mathrm{osc}}+R_{\text {test }}$.

devices from [11] and [3], respectively.

Even with the reasonable NPD value for the device, it should be noted that the power output is too low for direct applications. This, however, can be improved significantly by optimizing device parameters. Firstly, the gap distance between the proof mass and the counter electrodes should be minimized. Smaller gap will give larger intrinsic device capacitances, less sensitivity to parasitic capacitances and therefore 
higher output power. A gap of about $70 \mu \mathrm{m}$ has been used previously for a prototype device [13], and an even narrower gap of $38 \sim 70 \mu \mathrm{m}$ has been proved to be feasible [12]. Secondly, the surface charge density on the electrets should be increased by increasing both the bias voltage and the charging efficiency. Since the power output in general is proportional to the square of the surface charge density [6], we should expect 25 times higher power output when we increase the surface potential of the electret to $-700 \mathrm{~V}$. Last but of equal importance, the parasitic capacitance should be reduced. We have currently noticed a parasitic capacitance of about $40 \mathrm{pF}$ mainly from the measurement setup, which lowers the optimal load resistance and reduces the harvested power.

\section{Conclusion}

A MEMS compatible process flow has been developed for wafer level fabrication of a 2D electret-based energy harvesting device. Four wafers for a device stack were designed and fabricated i.e. top cap, main device, spacer and bottom electrodes wafers, respectively. Overall 44 devices are fabricated simultaneously on one 4 -inch wafer. The final device was packaged as a $1 \mathrm{~cm}^{2}$ chip using CYTOP both as an electret material and bonding interfaces between wafers. Electrical power was generated from two perpendicular vibration directions as the proof mass was driven to its resonance frequency. In a simple test setup, a maximum output power of $32.5 \mathrm{nW}$ was achieved with an external load of $17 \mathrm{M} \Omega$, under a harmonic source motion with an acceleration RMS amplitude of $0.03 \mathrm{~g}\left(\sim 0.3 \mathrm{~m} \cdot \mathrm{s}^{-2}\right)$ at a frequency of $179.5 \mathrm{~Hz}$. The chip harvests a relatively low power output in the current implementation due to the low intrinsic device capacitance and the large parasitic capacitance, while the normalized power density is very high thanks to the high mechanical quality factor. With further optimization, we expect a higher output power in the tens of micro watts range. The compatible fabrication process shows a promise for applications within the wireless sensor networks technology.

\section{Acknowledgements}

The authors would like to thank Mr. Anders Lei and Mr. Marco Triches for helpful discussions during this work. This project is supported by Danish Research Council for Technology and Production (Project No. 10-080864). Center for Individual Nanoparticle Functionality (CINF) is supported by the Danish National Research Foundation (DNRF54).

\section{References}

[1] H. Kulah and K. Najafi. An electromagnetic micro power generator for low-frequency environmental vibrations. In 17th IEEE International Conference on MEMS (MEMS'04), pages 237-240, 2004.

[2] S.P. Beeby, R.N. Torah, M.J. Tudor, P. Glynne-Jones, T. O'Donnell, C.R. Saha, and S. Roy. A 
micro electromagnetic generator for vibration energy harvesting. Journal of Micromechanics and Microengineering, 17(7):1257-1265, July 2007.

[3] Neil N.H. Ching, H.Y. Wong, Wen J. Li, Philip H.W. Leong, and Zhiyu Wen. A lasermicromachined multi-modal resonating power transducer for wireless sensing systems. Sensors and Actuators A: Physical, 97-98:685-690, 2002.

[4] R. Xu, A. Lei, C. Dahl-Petersen, K. Hansen, M. Guizzetti, K. Birkelund, E. V. Thomsen, and O. Hansen. Fabrication and characterization of MEMS-based PZT/PZT bimorph thick film vibration energy harvesters. Journal of Micromechanics and Microengineering, 22(9):094007, September 2012.

[5] S. Roundy and P.K. Wright. A piezoelectric vibration based generator for wireless electronics. Smart Materials and Structures, 13(5):1131, 2004.

[6] Y. Suzuki. Recent progress in MEMS electret generator for energy harvesting. IEEJ Transactions on Electrical and Electronic Engineering, 6(2):101-111, March 2011.

[7] A.M. Paracha, P. Basset, D. Galayko, F. Marty, and T. Bourouina. A silicon MEMS DC/DC converter for autonomous vibration-to-electrical-energy scavenger. IEEE Electron Device Letters, 30(5):481-483, 2009.

[8] Y. Sakane, Y. Suzuki, and N. Kasagi. The development of a high-performance perfluorinated polymer electret and its application to micro power generation. Journal of Micromechanics and Microengineering, 18(10):104011, 2008.

[9] S. Boisseau, G. Despesse, T. Ricart, E. Defay, and A. Sylvestre. Cantilever-based electret energy harvesters. Smart Materials and Structures, 20:105013, October 2011.

[10] T. Sterken, P. Fiorini, G. Altena, C. Van Hoof, and R. Puers. Harvesting energy from vibrations by a micromachined electret generator. In Int. Conf. Solid-State Sensors, Actuators and Microsystems, 2007, pages 129-32, 2007.

[11] H. Lo and Y.C. Tai. Parylene-based electret power generators. Journal of Micromechanics and Microengineering, 18(10):104006, 2008.

[12] Y. Naruse, N. Matsubara, K. Mabuchi, M. Izumi, and S. Suzuki. Electrostatic micro power generation from low-frequency vibration such as human motion. Journal of Micromechanics and Microengineering, 19(9):094002, 2009.

[13] M. Triches, F. Wang, A. Crovetto, A. Lei, Q. You, X. Zhang, and O. Hansen. A MEMS energy harvesting device for vibration with low acceleration. Procedia Engineering, 47:770-773, 2012.

[14] F. Wang and O. Hansen. Invisible surface charge pattern on inorganic electrets. IEEE Electron Device Letters, accepted.

[15] S.P. Beeby, M.J. Tudor, and N.M. White. Energy harvesting vibration sources for microsystems applications. Measurement Science and Technology, 17(12):R175, 2006.

[16] P.D. Mitcheson, E.M. Yeatman, G.K. Rao, A.S. Holmes, and T.C. Green. Energy harvesting from human and machine motion for wireless electronic devices. Proceedings of the IEEE, 96(9):14571486, 2008.

[17] K.E. Petersen. Silicon as a mechanical material. Proceedings of the IEEE, 70(5):420-457, 1982.

[18] A. Crovetto, F. Wang, , and O. Hansen. Modeling and optimization of an electrostatic energy harvesting device. to be published.

[19] F. Laermer, A. Schilp, K. Funk, and M. Offenberg. Bosch deep silicon etching: improving uniformity and etch rate for advanced MEMS applications. In 12th IEEE International Conference on MEMS (MEMS'99), pages 211-216, January 1999.

[20] F. Wang, C. Bertelsen, G. Skands, T. Pedersen, and O. Hansen. Reactive ion etching of polymer materials for an energy harvesting device. Microelectronic Engineering, 97:227-230, 2012.

[21] F. Wang and O. Hansen. Inorganic electret with enhanced charge stability for energy harvesting. In the 8th Annual IEEE International Conference on Nano/Micro Engineered and Molecular Systems (IEEE NEMS 2013), pages 207-210, April 2013.

[22] V. Leonov and R. van Schaijk. Patterning of inorganic electrets. IEEE Transactions on Dielectrics and Electrical Insulation, 17(4):994-1000, August 2010. 